\title{
Entre prescrições e sobrescrições: a experiência da leitura em ambiência digital ${ }^{1}$
}

\author{
Carina Ochi Flexor \\ Doutora; Universidade de Brasília, Brasília, DF, Brasil. \\ carina.flexor@unb.br
}

\section{Resumo}

O presente artigo busca refletir - com base nas discussões sobre o futuro da escrita em Flusser e, ainda, a partir da materialidade do livro digital - , sobre a experiência da leitura em ambiência digital. De abordagem dedutiva e partindo de uma perspectiva qualitativa, a partir da caracterização do livroaplicativo como exemplo de prescrição e os protocolos na leitura como uma espécie de sobrescrição, a investigação alcança resultados que apontam para a atualização do pacto de leitura que, por sua vez, indica a aceitação tácita do leitor em permitir ser lido pela plataforma-livro que, no que lhe concerne, também lê o seu leitor.

\section{Palavras-chave}

Livro-aplicativo. Experiência da leitura. Prescrição. Sobrescrição. Protocolos da leitura.

\section{Introdução}

Ao atentar-se para as palavras Legere Oculis, confronta-se com a ideia de colher com os olhos letras, palavras, linhas e, sobretudo, entrelinhas. Legere (ler) seria, então, um jeito de escolher e (re)colher rastros de linhas de outrem. Uma decodificação lenta que se transveste em imagens mentais particulares (CALVINO, 2008). Um ato que requer, historicamente, uma linha que se alinha com outras, formando um tecido/contexto que promove um refletir a partir de uma ideia de continum, conformando a noção acerca da consciência histórica (FLUSSER, 2010) que, por sua vez, nos permite (ou impede?) de refletir, mais amplamente, sobre as transformações ora em curso no campo editorial.

\footnotetext{
1 Uma primeira versão desse texto, na época intitulada Prescrições e o leitor contemporâneo: novas formas de ler o mundo, foi apresentada, tendo publicação em anais, no Simpósio Internacional de Inovação em Mídias Interativas (SIIMI), em 2016. Destaca-se que, embora as aproximações com Flusser já aparecessem na primeira versão, o texto aqui apresentando reflete o amadurecimento da pesquisa.
} 
Notadamente, as tecnologias digitais têm provocado significativas transformações, inclusive, nas concepções de tempo e espaço, nos processos comunicacionais, nas articulações sociais e, fundamentalmente, na conformação livresca em ambiência digital que, ademais, vem reverberando sobre a experiência do ler frente as interfaces gráficas dos distintos dispositivos de leitura. O que é produzido pelos códigos digitais pode estar, conforme afirmou Flusser (2010), se apresentando em todos os lugares, podendo ser atualizado a todo instante e, nesse sentido, as noções acerca de passado, presente e futuro e, sobretudo, espaço se atualizam, ganhando novos contornos. 0 contexto atual parece arrancar o leitor - de uma noção temporal linear que se reforçava no desenrolar do texto, por entre o passar das páginas de um livro - não mais do passado para o futuro (consciência histórica), mas do futuro ao encontro do presente.

Pensar o livro nesse contexto, outrossim, ultrapassa as discussões acerca dos deslumbramentos midiáticos que envolvem o uso do termo "digital", enquanto um qualificador do suporte sob o qual a matéria informacional se assenta (FLEXOR, 2012), pois este carrega em si mudanças significativas no ecossistema simbólico da linguagem e bases materiais e, consequentemente, no campo da sua produção, armazenamento, distribuição e recepção, demandando, assim, revisões acerca dos impactos sobre esse objeto historicamente arraigado na nossa cultura e, sobretudo, sobre as práticas em seu entorno.

Tal questão, sem dúvida, passa por compreender a natureza da new media (MANOVICH, 2001) que, ademais operar a partir da lógica dos algoritmos e estrutura de dados, faz notar que o objeto livresco hoje é conformado a partir da camada cultural dada pelas interfaces gráficas dos distintos artefatos tecnológicos, bem como pela camada computacional que, por sua vez, reivindica a colaboração de programadores na tessitura do objeto em si - fazendo ver vestígios aqui denominados de protocolos do sistema - que, a partir das lógicas de programação e suas linguagens, instrumentalizam os sistemas na realização de tarefas específicas, como a do ler, por exemplo.

Se a informação passa a ser lida por dispositivos ubíquos, facilitando a análise de um volume imenso de dados, permitindo, inclusive, o cruzamento de informações, antes, impensadas, então, tem-se hoje um potencial gigantesco de conexões relacionais sem precedente na história. Conforme registrou Flusser (2010) já vivemos um tempo -, que ganhamos mais tempo -, em que as máquinas fazem uma história melhor, mais rápida e variada do que já fizemos. Essa característica enciclopédica da sociedade do Big Data (LIMA JÚNIOR, 2011) torna o leitor um sujeito ativo - ele querendo ou não -, como uma espécie 
de leitor-inscritor. Diz-se isso, pois produzimos não só informações intencionais (produção ativa) -, como a publicação de informações no Instagram, por exemplo - , como também geramos um sem fim de informações por meio da geolocalização, preferências dadas a partir de likes etc (produção passiva). Isso, de outra forma, implica em um leitor ativo - antes restrito a participar por meio das lacunas interpretativas dadas pelos protocolos do autor (CHARTIER, 2011) -, frente a tessitura do objeto livresco, quando este é convocado a participar ativamente por meio de aportes de conteúdo multimodal - e dados - no tecer da obra. 0 leitor, então, por meio dos protocolos na leitura/no espaço ${ }^{2}$, como sobrescrições ${ }^{3}$ pois evanescentes, reivindicam sua cota na construção de suas obras de apreço, mudando, em definitivo, o cenário livresco e as experiências decorrentes. Destaca-se que se optou por denominar o leitor contemporâneo de leitor-inscritor, como citado, pois considera-se que este lê e escreve em um processo interativo de input e output do sistema livro e por considerar que inscrever, mais do que escrever, pode aqui denotar não só a ideia da produção e aporte de conteúdo multimodal - como sobrescrições (FLUSSER, 2010) -, como também, em sentido complementar, de inscrição, no sentido de indicar um registro mais profundo, gravado, como as escritas maquínicas da camada computacional. A adoção da palavra justifica-se também por remeter à ideia de inscrição como submeter seu nome a, relevando a imposição dos sistemas informáticos que faz lançar o perfil do usuário em rede, levando-o a assentir as políticas de uso e privacidade, colaborando com a captura de dados por meio dos rastros deixados pelos percursos em rede. Destarte, se a experiência da leitura frente ao objeto livro impresso foi fortemente atravessada pelos protocolos do autor e do editor - discutidos por Chartier (2011) -, o cenário atual, por fazer perceber a ingerência de outros atores que passam a fazer parte da tessitura do objeto, faz identificar uma espécie de atualização dos protocolos de leitura (FLEXOR, 2018) frente ao livro-aplicativo.

Diante desse contexto, então, o presente artigo buscou refletir - com base nas discussões sobre o futuro da escrita em Flusser e, ainda, a partir da materialidade do livro digital -, sobre a experiência da leitura em ambiência digital. Para isso, entretanto, de abordagem dedutiva e partindo de uma perspectiva qualitativa, o texto adota como arcabouço teórico não apenas Flusser $(1985,2008,2010)$ como, também, apoia-se em Chartier (2011) e Flexor (2018) a despeito das noções acerca dos protocolos de leitura e,

\footnotetext{
2 Flexor (2018), considerando a materialidade livresca e os protocolos de leitura de Chartier (2011), aponta para a ampliação dos atores que, participando da tessitura do objeto, imprimem vestígios que impactam sobre a leitura (protocolos do sistema e na leitura/no espaço).

3 Sobrescrição, segundo Flusser (2010), dentre muitos aspectos que o autor destaca, são escritas fugazes aplicadas em superfícies.
} 
ainda, Manovich (2002) a respeito da natureza da new media. Desse modo, a partir da caracterização do livro-aplicativo como exemplo de prescrição ${ }^{4}$ e os protocolos na leitura como uma espécie de sobrescrição, a investigação avança no sentido de compreender aspectos acerca desse leitor da pós-escrita (FLUSSER, 2010) e as reverberações que podem ser observadas quando da experiência da leitura em ambiente digital.

Por fim, se o leitor lê e ler (legere) é antes escolher, nosso espectro de leitura estaria, então, reduzido às escolhas permitidas pelos aparelhos/caixa preta (FLUSSER, 1985) e suas tecnologias preditivas? Se a possível morte anunciada da escrita alfabética, ressaltada por Flusser (2010), for, enfim, verdade, o objeto que consagrou a escrita, o livro, também morrerá e assim não teremos mais leitores de livros? Se somos herdeiros do livro ocidental e de uma escrita linear decorrente dessa filiação, de quem herdaríamos esse novo modo de ler oriundo dos códigos binários? Que tipo de leitor estará sendo gestado frente às prescrições próprias dos livros digitais? Se o leitor hoje participa da tessitura do objeto livresco, a partir de aporte de conteúdo multimodal e dados, seria o ler, assim como o escrever, como aponta Flusser (2010), um gesto (político) expressivo que se volta ao encontro de um outro leitor? Somos, então, leitores-funcionários a serviço dos aparelhos? Quem são esses leitores? Homens? Aparelhos?

Essas e tantas outras inquietações é que motivaram o desenvolvimento de muitas outras pesquisas já realizadas e, em especial, desse texto que, por sua vez, não pretende ser resposta, do contrário, deseja ser, antes, um espaço-tempo para ampliar algumas das muitas perguntas que circundam o produto livresco e as práticas em seu entorno.

\section{A experiência da leitura: entre prescrições e sobrescrições}

A questão do livro digital, diante das mudanças culturais na era da pós-história (FLUSSER, 2010) ou pós-informação (NEGROPONTE, 1995), parece exigir que se ultrapasse - embora, ainda, considere - as discussões tecnológicas focadas nas transformações materiais e processos vinculados ao livro impresso. Antes, a problemática instaurada diante da possibilidade de digitalização do objeto livresco em contextos de desterritorialização informacional (LEMOS, 2003) e sob artefatos de conexão contínua diz de uma revisão desse objeto que legitimou o modelo de pensamento assimétrico e fonocêntrico da escrita (DERRIDA, 1976) e que influenciou, se não definiu, um modelo de livro que, por sua vez,

${ }^{4}$ Prescrições, conforme registra Flusser (2010), referem-se ao programar, a linguagem binária que se dirige às máquinas. 
gestou uma leitura que observara a linearidade da escrita e do próprio objeto. Uma matriz de linguagem que levou Flusser (2010) a afirmar que a consciência histórica nasce da escrita linear e que o pensamento ocidental é histórico no sentido de que concebe o mundo em linhas, como um processo ou sucessão de acontecimentos que insiste em levar a humanidade ao futuro. Afirmou, ainda, que a escrita unidimensional permite ao leitor refletir sobre o que lê, colocando, como ele mesmo registra, os "pensamentos nos trilhos", ressaltando, ainda, que parece ser compreensível que se pense que a figura do escritor tenha surgido da necessidade de superação do homem em vencer o tempo e de "endurecer a memória" (FLUSSER, 2010).

Dessa forma, o objeto da leitura e a própria leitura em si reforçaram, ao longo da história, o princípio da linearidade, uma vez que, de acordo com Saussure (1991, p. 84), a escrita herda da oralidade a lógica da sequência temporal na qual o signo auditivo se desenvolve em uma extensão passível de ser mensurada em apenas uma dimensão, uma linha, fazendo observar que de tempos remotos às escritas mais contemporâneas a linha permanece enquanto estrutura fundante e princípio gráfico-visual ordenador da escrita, do livro e da leitura (FLEXOR, 2012).

Um objeto que, ao longo do tempo, fez da escrita sua raiz, predestinando à imagem uma história que faz ver a luta em se alcançar o centro das narrativas. Esta última, embora por princípio fundante tenha se generalizado em padrões mais universais, manteve-se subordinada aos hábitos de leitura impostos pela escrita, legitimados, inclusive, por leis de organização sintática atestadas pela Teoria da Gestalt, que, por sua vez, preconiza uma leitura que é orientada por um fluxo que se dá da esquerda para a direita e de cima para baixo.

Diante do exposto, procede observar que a crise anunciada pelo livro na contemporaneidade - que, notadamente, impacta sobre a experiência do ler - diz de questões que vão além da sua materialidade, apontando para a revisão acerca da ideia de verdade histórica imposta pelo verbo, do escritor enquanto figura de (autor)idade, das particularidades das matrizes de linguagem que compelem modos próprios de leitura, o que indica mais amplamente a necessidade de se examinar os modos de produção, difusão e acesso ao conhecimento humano a partir de um contexto em que o livro impõe uma condição própria, destinando ao verbo múltiplos caminhos e elegendo a imagem como principal elemento de acesso ao conteúdo mesmo. Assim, mais que revisitar a história do livro a partir da lente hegemônica, sob a qual o livro se consolidou no tecido social, cabe 
reconhecer as transformações estabelecidas culturalmente a partir dos múltiplos caminhos possíveis da escrita, que, por sua vez, se mostra entremeada quando da prescrição livresca e, sobretudo, pela reversão hierárquica para com a imagem.

Dentre as muitas variantes que poderiam ser aqui citadas, livro e leitura, muito além de se submeterem aos interesses político-ideológicos de cada época, respondem, também, às possiblidades e/ou limitações materiais e de produção de cada período. Mais que isso, a matriz da linguagem dominante não só orienta as maneiras de conformação do objeto da leitura como, sobretudo, indica os modos de acesso ao conteúdo informacional, além de agir, diretamente, sobre os processos de subjetivação e cognição. A leitura como prática de apropriação cultural sempre esteve condicionada às formas de apresentação dos textos, em função das maneiras como é transmitido (CHARTIER, 2011). Se os modos de reprodução de outrora permitiram uma maior expansão da leitura por meio do número de títulos padronizados pela lógica do livro histórico, a multiplicação em distintas interfaces gráficas dos dispositivos de leitura faz do livro hodierno um conjunto de conteúdos pulverizados aqui e ali e que se apresentam de forma responsiva e ao sabor de escolhas que são antes dadas por cada leitor.

Dessa discussão decorre a necessidade de também tecer revisões acerca dos sujeitos envolvidos no contexto editorial, em especial o próprio leitor, uma vez que os modos de ler são antes impactados por implicações demarcadas por autores, editores, impressores, distribuidores, vendedores e todos os demais agentes que participam da cadeia livresca (CHARTIER, 2011; DARNTON, 2010). Chartier (1999), nesse quesito, ainda destaca que na dimensão material os objetos culturais são constituídos por indivíduos mediante os processos de produção, circulação e recepção, tornando-se essencial compreender as motivações e os efeitos da materialidade de tais objetos, uma vez que reconhece o "[...] controle que editores ou autores exercem sobre essas formas encarregadas de exprimir uma intenção, de governar a recepção, de reprimir a interpretação" (CHARTIER, 1999, p. 35).

A despeito, Flusser (2010) registra que a atividade da escrita exige um leitor, a quem o desenrolar dos sinais gráficos, escolhas estilísticas são feitas na conformação da escrita, desde a escolha da língua até seu gênero e modos de apresentação, prevendo, dessa forma, seus leitores-modelos. Segundo Eco (1988), prever o próprio leitor-modelo não implica em esperar que este exista, mas sim que se deve mover o texto no sentido de construí-lo. Assim, ao longo do tempo, o livro impresso fez articular protocolos de leitura (CHARTIER, 2011) e práticas consonantes com suas bases materiais, históricas e culturais, fazendo despontar 
uma materialidade que deliberou vestígios condutores da leitura demarcados por autores e editores e que fez determinar não só a relação livro-leitor, como colaborou para a consolidação de um legente por este objeto constituído. Um leitor que fora tecido e reafirmado ao longo de uma longa história e que, ademais as particularidades dos objetos e dos legentes constituídos por/em cada obra, fez gestar, no seio da cultura, um leitor-modelo (ECO, 1988) próprio do livro impresso que, disposto a se entregar a uma experiência antes solitária e silenciosa, acostumou-se a deslizar os olhos sobre a linearidade do verbo - e do próprio objeto -, implicando-se em uma atividade concentrada, do espaço privado e da participação, preponderantemente, dirigida às lacunas interpretativas dadas por meio dos protocolos do autor.

No âmbito do livro em ambiência digital, antes de adensar as discussões acerca das transformações no que se refere a sua materialidade - e sua lógica prescritiva - e, ainda, os impactos sobre o ler a partir das sobrescrições dadas a partir dos protocolos na leitura, cabe antes reconhecer duas categorias livrescas que apontam para manifestações distintas e parâmetros próprios de leitura. Ressalta-se que, para o presente trabalho, adotou-se como objeto empírico para fins de observação os objetos livrescos denominados de livrosaplicativos (appbooks), deixando à margem das discussões aqui apresentadas a categoria de livros-arquivos. A escolha se justifica, uma vez que, deslocando o interesse para as transformações sobre a experiência da leitura em ambiente digital, os livros-aplicativos, diferentemente dos livros-arquivos, se enquadram no universo dos softwares e, nesse sentido, tornam-se terreno de interesse para a investigação proposta, sobretudo, por operar a partir da pragmática computacional. De outra forma, os appbooks, como exemplo de prescrições se apresentam como terreno interessante para a investigação acerca da experiência da leitura, fundamentalmente, pelo reconhecimento de que as linguagens maquínicas imputam no objeto - por meio dos protocolos do sistema - parâmetros que atravessam significativamente a experiência do ler. A crise, então, que ameaça a escrita, anunciada por Flusser (2010), é decorrente não apenas da textolatria em que o homem se deixou conduzir, mas, sobretudo, porque a própria escrita tem sofrido modificações na sua forma linear de apresentação, em função da lógica maquínica, cuja escrita é organizada por elas próprias, obedecendo ao código não-alfabético, o binário.

Assim, a gênese das mudanças nos modos de ler na contemporaneidade apontam para transformações advindas da materialidade livresca, uma vez que indicam o descolamento da matéria a ser lida dos suportes de outrora - quando as particularidades 
técnicas envolvidas na sua confecção ajudaram a definir os seus próprios atributos, como no caso do cinema, da fotografia, da pintura e, também, do livro (MANOVICH, 2013) -, alicerçando-se em uma base comum manifesta a partir da convergência de mídias e linguagens, reunindo lógicas de mineração de dados e propriedades de software. Outrossim, como já destacado, o livro-aplicativo é resultante da articulação entre camadas que fazem reconhecer o estrato mais profundo - a computacional e sua sintaxe própria -, o estrato mais superficial - a camada cultural com suas leis de organização e affordances. É possível reconhecer os softwares como uma espécie de interface computacional/cultural, viabilizando diálogos que possibilitam a realização de distintas tarefas por parte do leitor. Embora a linguagem maquínica enseje em si os softwares, reconhece-se que são esses que viabilizam funções, antes dadas na cultura, possibilitando a execução de variadas tarefas.

Diante do exposto e reconhecendo as mudanças promovidas na instância do livro e no lastro cultural no qual se insere, vislumbra-se - acerca dos protocolos de leitura propostos por Chartier (2011) frente ao livro impresso - que o livro-aplicativo, a partir da sua materialidade, parece reivindicar a existência de índices - que direcionam a leitura que lhe são bastante particulares. Ao se investigar a natureza mesma do livro em contextos digitais, percebe-se que este passa a englobar, no processo próprio de sua construção e (re)construção - dada a abertura da obra a apropriações de múltiplos leitores -, outros atores que passam a postular vestígios ou protocolos de leitura endereçados aos muitos legentes, transformando, decerto, as experiências leitoras.

Nesse horizonte, além dos já reconhecidos protocolos identificados por Chartier os de autoria e os de edição -, torna-se fundamental legitimar outros condutores de vestígios implicados na matéria livresca, a saber: os protocolos do sistema e os protocolos na leitura / protocolos no espaço.

Propiciada pela quebra do polo da emissão e ubiquidade dos hardwares, a matéria livresca se abre às apropriações de múltiplos leitores que, por sua vez, originam vestígios aqui denominados de protocolos na leitura, de outra maneira, vestígios gerados por múltiplos legentes - durante a experiência da leitura em si -, a partir de aportes de conteúdos de diversas naturezas. Ainda sobre esses últimos, podem incidir, ainda, protocolos no espaço, vestígios demarcados na experiência mesma e que se efetivam nos deslocamentos cotidianos dos sujeitos quando da leitura em si.

Admitir, nos livros-aplicativos, os protocolos do sistema é aceitar que a sua natureza material, fundamentalmente a partir da camada computacional mediada por 
software, endereça vestígios à leitura e, nesse sentido, o leitor seria, a partir da perspectiva flusseriana, funcionário do aparelho (FLUSSER, 1985). De outra forma, sua experiência de leitura estaria sendo balizada pelas inscrições maquínicas, uma vez que as tarefas possíveis de um dado softwares de leitura só se efetivam no campo da experiência mesma se/como os protocolos de tais hardwares/softwares são programados. Como camada recoberta pelas interfaces gráficas - parte visível desse tipo de manifestação livresca -, a camada computacional e sua linguagem não-alfabética, se configuraria como caixa-preta (FLUSSER, 1985), desafiando a experiência da leitura, sobretudo, quando se observa que, a partir da colaboração do leitor como sobrescrições - protocolos na leitura/no espaço -, o objeto livresco, a partir da pragmática computacional, passa a ler também o seu leitor.

\section{Considerações finais}

Com o avanço tecnológico dos livros digitais e com as mudanças que a nossa compreensão sofreu quanto a relação espaço-temporal, cada aparelho passou a requerer determinada prescrição, termo que, para Flusser (2010), acompanha o homem antes da própria máquina, relacionando-se a um modo de comportamento. Se a revolução industrial teve papel relevante no estabelecimento de normas de comportamento homem-maquínico, a revolução da informática, por sua vez, propiciou novos padrões, novas prescrições em relação aos programas desses aparelhos. Para Flusser (2010), o programa é uma obra escrita que não se dirige a seres humanos, mas aos artefatos construídos pelos homens e se assim o é, a escrita, notadamente da sociedade pós-industrial, se assenta sobre o código binário. É a organização desses dados que permite a criação de programas - softwares que prescrevem aos aparelhos como devem ser o seu funcionamento (OLIVEIRA, 2012), ditando, desse modo, os modos de acesso e as experiências daí decorrentes.

Nesse horizonte, então, infere-se que opera no interior dos aparelhos contemporâneos, mediadores da leitura, prescrições que, a partir das sobrescrições atualizadas/autorizadas tacitamente pelos leitores, viabilizam as predições, ampliando, então, as discussões acerca da ideia de liberdade e coerção (CHARTIER; CAVALLO, 1998) da atividade leitora no contexto contemporâneo.

Mais além, se o livro - depositório da escrita -, ao longo de sua história suplantou um sem fim de resistências, estabelecendo-se por meio da força da linguagem que lhe conferiu a sua forma, influenciando leitores de diversos tempos, o que poderemos esperar 
de um livro que viabiliza a experiência da leitura a partir de lógicas prescritivas que operam no interior de caixas-pretas protocolos dirigidos aos muitos iletrados?

Sem dúvida, tais mudanças, mais do que rupturas com a tradição livresca, denunciam, antes, alterações profundas no modo de escrever, de ler e, sobretudo, de pensar. Por fim, se levarmos a cabo que só no gesto do escrever podemos expressar a existência humana (FLUSSER, 2010), como, então, expressaremos e garantiremos a nossa existência com a supremacia da prescrição?

\section{Referências}

CALVINO, Ítalo. Seis propostas para o próximo milênio. São Paulo: Companhia das Letras, 2008.

CHARTIER, Roger. Práticas da leitura. Tradução Cristiane Nascimento. 5ª. Edição. São Paulo: Estação Liberdade, 2011.

CHARTIER, Roger. A ordem dos livros: leitores, autores e bibliotecas na Europa entre os séculos XIV e XVIII. Brasília: Editora da Universidade de Brasília, 1999.

CHARTIER, Roger; CAVALLO, G. (Orgs.). História da leitura no mundo ocidental 1. São Paulo: Ática, 1998.

DARNTON, Robert. A questão dos livros: passado, presente e futuro. São Paulo: Companhia das Letras, 2010.

DERRIDA, Jaques. Gramatologia. São Paulo: Perspectiva, 1976.

ECO, Umberto. Lector in fabula. São Paulo: Perspectiva, 1988.

FLEXOR, Carina Luisa Ochi. Appbook raízes: bibliogênese e devir livro. 2012. Dissertação (Mestrado em Cultura Visual) - Programa de Pós-Graduação em Arte e Cultura Visual, Universidade Federal de Goiás, Goiânia, 2012.

FLEXOR, Carina Luisa Ochi. Da ontologia livresca à experiência da leitura em contexto digital: entre a consonância e o conflito. 2018. Tese (Doutorado em Arte e Cultura Visual) Faculdade de Artes Visuais, Universidade Federal de Goiás, Goiânia, 2018.

FLUSSER, Vilém. A filosofia da caixa preta. São Paulo: Hucitec, 1985.

FLUSSER, Vilém. 0 universo das imagens técnicas: elogio da superficialidade. São Paulo: Annablume, 2008.

FLUSSER, Vilém. A escrita: há futuro para a escrita? São Paulo: Annablume, 2010.

LEMOS, André; CUNHA, Paulo (org.). Olhares sobre a cibercultura. Porto Alegre: Sulina, 2003. 
LIMA JÚNIOR, Walter Teixeira. Jornalismo computacional em função da "Era do Big data". Líbero, São Paulo, v. 14, n. 28, p. 45-52, 2011.

MANOVICH, Lev. The language of new media. Cambridge: MIT Press, 2001.

NEGROPONTE, Nicholas. A vida digital. São Paulo: Companhia das Letras, 1995.

OLIVEIRA, Danusa. 0 escritor e o leitor na era digital à luz de Flusser. Design Arte, Moda e Tecnologia. São Paulo: Rosari, Universidade Anhembi Morumbi, PUC-Rio e Unesp-Bauru, 2012, p. 330-344.

SAUSSURE, Ferdinand de. Curso de linguística geral. São Paulo: Cultrix, 1991.

\title{
Between prescriptions and superscriptions: the experience of reading in a digital environment
}

\begin{abstract}
This article seeks to reflect - based on discussions about the future of writing in Flusser and, also, from the ontology of the digital book - on the experience of reading in a digital environment. From a deductive approach and from a qualitative-exploratory perspective, from the characterization of the application book as an example of prescription and the protocols in reading as a kind of overwriting, the study achieves results that point to the updating of the readout pact that, in turn, it indicates the tacit acceptance of the reader to allow being read by the platform-book which, as far as he is concerned, also reads his reader.
\end{abstract}

\section{Keywords}

Application book. Reading experience. Prescription. Overwriting. Reading protocols.

Recebido em 30/05/2020

Aceito em 13/06/2020 